AperTO - Archivio Istituzionale Open Access dell'Università di Torino

\title{
Novel investigational therapies for treating biliary tract carcinoma
}

\section{This is the author's manuscript}

Original Citation:

Availability:

This version is available http://hdl.handle.net/2318/1615655

since 2017-05-12T15:18:44Z

Published version:

DOI:10.1080/13543784.2016.1252330

Terms of use:

Open Access

Anyone can freely access the full text of works made available as "Open Access". Works made available under a Creative Commons license can be used according to the terms and conditions of said license. Use of all other works requires consent of the right holder (author or publisher) if not exempted from copyright protection by the applicable law. 


\section{Novel investigational therapies for treating biliary tract carcinoma}

\section{Tampellini, A La Salvia \& GV Scagliotti}

To cite this article: M Tampellini, A La Salvia \& GV Scagliotti (2016): Novel investigational therapies for treating biliary tract carcinoma, Expert Opinion on Investigational Drugs, DOI: 10.1080/13543784.2016.1252330

To link to this article: http://dx.doi.org/10.1080/13543784.2016.1252330

Accepted author version posted online: 22

Oct 2016.

Submit your article to this journal

Џ Article views: 1

Q View related articles $\asymp$

View Crossmark data $\asymp$ 
Publisher: Taylor \& Francis

Journal: Expert Opinion on Investigational Drugs

DOI: $10.1080 / 13543784.2016 .1252330$

\section{Novel investigational therapies for treating biliary tract carcinoma}

\section{Tampellini M, La Salvia A, Scagliotti GV}

University of Turin, Department of Oncology, AOU San Luigi di Orbassano, Torino, Italy.

\section{Corresponding Author:}

Marco Tampellini

University of Turin

Department of Oncology

AOU San Luigi di Orbassano

Regione Gonzole, 10

10043 Orbassano, Torino, Italy

Tel +390119026017

Fax +390119026992

e-mail marco.tampellini@unito.it 
Keywords: Cholangiocarcinoma review; target therapy; Next Generation Sequencing; Prognostic biomarker 


\begin{abstract}
Introduction: Cholangiocarcinoma (CCA) is an epithelial cell malignancy arising from bile ducts and/or peribiliary glands. Even though it is considered as a rare neoplasm, its incidence is raising, particularly in developed countries. Prognosis is generally poor with few patients who present the inclusion criteria for surgery (the mainstay treatment for this tumour). Several genetic alterations potentially driving tumour progression have been described, representing a possible target for new compounds.
\end{abstract}

Areas covered: A clinical trial search in Clinicaltrials.gov encompassing a literature search in PubMed and ASCO/ESMO Websites was undertaken in March 2016.

Expert opinion: Notwithstanding a large number of drug tested, results are still disappointing. The main reasons could be the low number of patients enrolled in trials, and the lack of a patient selection based on the biological profile of the tumours. Potential active drugs could have been discharged simply because beneficial in a particular subgroup of patients and not in un unselected population. The future direction of the research should consider biomarker evaluation in order to describe the genetic alteration/s that/drive tumour progression and aggressiveness and the mechanisms of drug resistance. Finally, it will be of great interest to consider the results of immunotherapy whenever available. 


\section{Article highlights}

- Cholangiocarcinoma is a rare cancer and its incidence is raising particularly in developed countries. Many genetic alterations have been described, giving rationale for the development of new treatment strategies

- Anti-EGFR therapies have been extensively studied in cholangiocarcinoma patients. Notwithstanding encouraging preliminary results, comparison trials did not demonstrate superiority of cetuximab or panitumumab plus chemotherapy versus chemotherapy alone. A new pan-HER oral inhibitor is being tested

- Several specific inhibitors directed to mTor, ABL, PI3K/AKT, Farnesyltransferase, proteasome, and VEGF failed to demonstrate significant clinical activity in unspecific patient population.

- Results from trial selecting patients with specific genetic alterations (FGFGR, IDH, ALK, ROS1, NTRK) or from trial that explore the role of drugs with new mechanisms of action (oxygen modulators, pan-IDH1 mutant inhibitor, PARP 1/2 inhibitor) will help researchers to shed light on the mechanisms underlying tumour progression

- The characterization of the genetic profile of each single tumour will pave the way for personalized and hopefully efficacious therapies. 


\subsection{Introduction}

Cholangiocarcinoma (CCA) is an epithelial cell malignancy arising from intrahepatic (IH) and extrahepatic $(\mathrm{EH})$ bile ducts and/or the peribiliary glands [1]. EH disease represents about 40\%, perihilar disease $50 \%$ and $\mathrm{IH}$ disease less than $10 \%$ of cholangiocarcinoma cases. The incidence is globally raising, particularly in developed countries, accounting for up to 2 new cases every 100.000 inhabitants per year $[1,2]$. The mainstay treatment for this type of neoplasia is surgery. However, only approximately one half of the patients is suitable for resection and surgical techniques are rather complex, often necessitating lobar hepatic and bile duct resection, regional lymphadenopathy, and Roux-en-Y hepaticojejunostomy. Liver transplantation with neoadjuvant chemoradiation is a valid therapeutic alternative. However, only few patients present the strict inclusion criteria for transplantation. As a whole, prognosis of CCA is generally bad, with mortality rate of 1.4 per 100.000 inhabitants per year, an ayerage.

After the publication of the ABC-02 study results [3] chemotherapy with Cisplatin and gemcitabine is considered the standard of care in locally advanced or metastatic CCA, with some alternatives equally considered as standard of care such as gemcitabine/oxaliplatin, or Gemcitabine/Capecitabine. Notwithstanding positive results with chemotherapy, median survival is poor with a life expectancy of no more than 12 months. Contemporary research techniques allowed the identification of several genetic changes contributing to the selective growth advantage of CCA cancer cells[1]. The most studied signalling networks in CCA biology is the RAS-MAPK pathway, followed by VEGF, PI3K/mTOR, HER2/neu and MET pathways. Thus, the number of clinical trials with targeted therapy alone or in combination with traditional chemotherapy is expanding, and new drugs are in early stages of investigation.

In this review we focus the attention on new drugs and new strategies currently under investigation in the treatment of biliary tract carcinomas. Where not otherwise specified, reported studies included patients with either $\mathrm{IH}$, and $\mathrm{EH}$, and peribiliary glands. 


\section{Anti HER family}

\subsection{Agents at later stage of development}

\subsubsection{Anti-EGFR monoclonal antibodies: cetuximab and panitumumab}

The EGFR pathway has been identified as a promising molecular target in CCA. In fact, overexpression of EGFR was found in $38 \%-100 \%$ of the tumour samples, almost all in the gene sequence coding for the tyrosine kinase domain found in exon 21 [4].

Cetuximab (Erbitux ${ }^{\mathrm{TM}}$, Merck) is a recombinant human-mouse chimeric IgG1 monoclonal antibody binding EGFR with high affinity approved for the treatment of patients with metastatic colorectal cancer (CCR) and head and neck cancer [5-7].

The efficacy of cetuximab in CCA was firstly reported in a retrospective analysis evaluating the outcomes of five patients with stage IV or not completely resected tumours receiving cetuximabcontaining therapy. After treatment, four patients experienced a clinical response (one complete) and one disease stabilization. [8]. Notwithstanding these encouraging results, subsequent and larger clinical trials reported contrasting results. In a multi-centre phase II trial 44 patients with CCA received cetuximab and gemcitabine. The study met its primary endpoint as six months progression free survival (PFS) was 47\%. Median overall survival (OS) was 13.5 months and nine patients (20.4\%) had partial response (PR) with an overall disease-control rate (DCR) of $79.5 \%$ [9]. In a non-comparative, open-label, randomised phase 2 trial, recruiting patients with non-resectable or metastatic cholangiocarcinoma, gallbladder carcinoma, or ampullary carcinoma, 150 patients were randomly assigned to receive gemcitabine and oxaliplatin (GEMOX) with or without cetuximab. Clinical outcomes resulted to be comparable in the two arms as median PFS was $6 \cdot 1$ months in the chemotherapy plus cetuximab group and 5.5 months in the chemotherapy alone group, whereas median overall survivals were 11 vs 12.4 months, respectively [10]. 
Cetuximab treatment seems to be beneficial particularly in patients with intrahepatic CCA. In fact in an open-label pilot study of nine patients progressing after GEMOX the addiction of cetuximab permitted to obtain a tumour shrinkage in two $(22 \%)$ of them [11]. Gruenberger et al published a single-arm phase II study of GEMOX and cetuximab demonstrating an overall response rate of $63 \%$, including 3 patients with a complete response. The majority of the patients in this trial had intrahepatic cholangiocarcinoma (60\%). The study did not limit recruitment to patients with KRAS wild-type tumours, and interestingly, partial responses were observed in two of the three patients with KRAS mutant tumours. The interim analysis of the first 36 patients revealed an improvement in PFS rate at four months of the experimental arm vs placebo (61 vs. 44\%) [12].

Recently, the results of a randomised, phase II study of GEMOX with or without cetuximab conducted in Asian countries confirmed that the combination was not statistically superior to chemotherapy alone. Response rate, primary endpoint of the study, did not differ between the two $\operatorname{arms}(27 \%$ vs $15 \%$ with vs without cetuximab, respectively, $\mathrm{p}=0.12)$. Median PFS were 6.7 vs 4.1 $(p=0.05)$ and median OS 10.6 vs 9.8 months $(p=0.91)$ [13]. Interestingly, KRAS status seemed not to influence clinical outcomes. Key results of the above described trials are summarized in Table 1.

Panitumumab (Vectibix TM, Amgen) is a fully humanized IgG2 monoclonal antibody. It was generated in transgenic strains of mouse and modified to express human immunoglobulin genes (XenoMouse). Panitumumab is approved only for the treatment of metastatic colorectal cancer patients [14].

In CCA, encouraging results were reported in 42 patients with KRAS wild-type tumours enrolled in a phase II trial exploring the activity of the combination of GEMOX with capecitabine and panitumumab. Overall response rate (ORR) was $33 \%$ with a DCR of $86 \%$, median PFS of 8.3 months,6-month PFS rate of $71 \%$, and a median OS of 9.8 months [15]. These results were furtherly confirmed in a phase II study enrolling 31 patients with locally advanced or metastatic 
KRAS wild-type CCA treated with GEMOX + panitumumab: ORR was 45\%, median PFS 10.6 months and median OS 20.3 months [16].

A phase II study enrolling 35 patients with advanced CCA and treated with gemcitabine, irinotecan and panitumumab reported a ORR of $31 \%$, a median PFS of 9.7 months with a 5 -month PFS rate of $69 \%$ (primary aim of the study) and a median OS of 12.9 months. Interestingly, patients were recruited regardless the KRAS status of their tumours, obtaining clinical outcomes similar to those reported from patients with KRAS wild-type tumours [17].

These encouraging results were not confirmed in an Italian open-label phase II trial randomising patients with advanced KRAS wild-type CCA to receive GEMOX with (arm A) or without (arm B) panitumumab. Primary endpoint of the study was PFS. Eighty-nine patients (45 in arm A and 44 in arm B) were enrolled between June 2010 and September 2013. After a median follow-up of 10.1 months, the median PFS was 5.3 months in arm A and 4.4 months in arm B ( $=0.27)$. No survival difference was observed: median OSs were 9.9 vs 10.2 months, respectively $(p=0.42)$. In a preplanned subgroup analysis, no difference in PFS was demonstrated according to the site of the primary tumour [18].

An ongoing trial conducted in Denmark aims to compare PFS of patients with advanced CCA randomly allocated to chemotherapy group (GEMOX + capecitabine) or to chemotherapy plus panitumumab. Patients are enrolled regardless the KRAS status of their tumours. Estimated enrolment is 70 patients, but the study is not yet recruiting (ClinicalTrials.gov Identifier: NCT00779454). Key results of the above described trials are summarized in Table 2.

\subsubsection{Anti-EGFR TKIs: erlotinib}

Erlotinib (Tarceva ${ }^{\mathrm{TM}}$ ) reversibly binds the intracellular kinase domain of EGFR inhibiting the ATPdependent activation of downstream pathway enzymes. It is currently approved for the treatment of 
EGFR mutant non-small cell lung cancer (NSCLC) as single agent and of pancreatic cancers in combination with gemcitabine [19].

A potential efficacy of erlotinib in CCA was firstly reported as single agent in a phase II study enrolling 43 patients at any line of therapy. Three partial responses were observed, for an oyerall response rate of $8 \%$ [20]. Data from a randomized, phase III, placebo controlled trial recruited a total of 285 patients who received GEMOX with erlotinib or placebo. Median PES of the experimental arm was 5.8 months vs 4.2 months of the placebo group $(\mathrm{p}=0.08)$. Median OSs were 9.5 months and were similar in both groups [21]. The combination of erlotinib and bevacizumab was tested in a phase II, multicentre study enrolling 49 patients with adyanced CCA. Six patients obtained confirmed PR, for an ORR of $12 \%$, whereas median OS was 9.9 months, and median TTP was 4.4 months [22]. Finally, a phase II trial (NCT01093222) evaluated the combination of sorafenib with erlotinib in patients with locally advanced, unresectable or metastatic CCA. Treatment was administered to 34 patients resulting in a median PFS of 2 months and in a median OS of 6 months. Treatment was toxic, with an incidence of SAE in about $50 \%$ of the patients, including $17 \%$ of toxic deaths, $8 \%$ of which for gastrointestinal toxicity or sepsis.

\subsubsection{Anti HER2 monoclonal antibodies: trastuzumab}

Trastuzumab is a humanized monoclonal antibody that selectively binds HER2 receptor. It is currently approved in the treatment of breast and gastric cancer patients [23,24].HER-2 overexpression has been found in about $5 \%$ of CCA, justifying the interest of the clinicians towards HER 2 inhibitors in this setting [25,26].

Some sporadic experiences of trastuzumab treatment in patients with CCA have been reported in literature as single agent or in combination with paclitaxel [27,28]. After having screened 53 patients with locally advanced or metastatic gallbladder cancer or CCA, a phase II study submitted a total of four patients to trastuzumab monotherapy. Two out of the three evaluable patients 
responded, with an ORR of $66.6 \%$. No information about the histology of the recruited patients was available (NCT00478140). These results were not confirmed in a retrospective analysis of five patients with advanced gallbladder or CCA harbouring HER2 mutations or overexpression and treated with anti HER2therapy: while patients with gallbladder tumours beneficiated from therapy, no response among patients with CCA was observed and all the patients progressed while on treatment with trastuzumab [29].

\subsubsection{Anti-HER2 TKIs: lapatinib}

Lapatinib is an orally active, dual inhibitor of HER2 and EGFR approved in breast cancer patients. In in vitro studies lapatinib demonstrated superior inhibiting activity than trastuzumab in CCA cell lines [26].

Despite preclinical evidences, lapatinib did not show any activity in CCA. A phase II study with lapatinib was stopped early as no clinical response has been observed in the first nine enrolled patients [30], whereas in another study the response rate of 17 patients with CCA was $0 \%$, with a median PFS of 1.8 months and a median OS of 5.2 months [31]. It has to be underlined, however, that in both studies no biomolecular selection has been made before patients enrolment.

\subsection{Novel anti-HER agents}

\subsubsection{ASLAN001}

ASLAN001 (Aslan Pharmaceuticals, Array-Biopharma), a novel oral pan-HER inhibitor, has shown clinical activity in both HER2-positive and EGFR-positive tumours. ASLAN001 is currently under development in HER2 expressing-cancers such as breast and gastric cancers.

A phase II multicentre study is recruiting patients with advanced or metastatic CCA (excluding peribiliary glands) who progressed after at least 1 line of systemic therapy to receive ASLAN001. Primary endpoint of the study is ORR, and secondary endpoints are the description of the safety 
profile of the drug, duration of response, PFS, OS, and DCR according to EGFR/HER2 status of the tumours (NCT02609958). The study will enrol a total of 25 patients in Asian countries, and it will be stopped if any response is observed in the first 10 patients. Recruitment has started in October 2015 and it is estimated to end in June 2017.

No information on ASLAN001 safety profile is yet available.

\section{3. mTOR inhibitors}

\subsection{Everolimus}

The mTOR pathway is known to be up-regulated in many cancer types, and preclinical evidences indicate that its inhibition may be effective in the treatment of CCA $[32,33]$. To date, everolimus is authorized for the treatment of patients with advanced breast cancer, neuroendocrine tumour and renal cell carcinoma. [34-37].

Few experiences of anti mTOR therapy in patients with CCA have been reported. A phase II Italian study (EUDRACT 2008-007152-94) explored the role of everolimus 10mg daily in locally advanced or metastatic CCA patients refractory to standard chemotherapy. Primary end points of the study were DCR and ORR that resulted to be $44.7 \%$ and $5.1 \%$, respectively. One patient had a partial response and one had a complete response lasting more than 8 months. Median PFS was 3.2 months, median OS was 7.7 months, and median TTP was 2.0 months [38]. A phase I study evaluated the combination of everolimus with gemcitabine (Cohort I) and with gemcitabine and cisplatin (Cohort II) in patients with advanced tumours (including CCA) refractory to standard chemotherapy. As an expansion cohort, 10 patients with advanced gallbladder cancers were treated with the maximally tolerated dose of cohort II: everolimus $5 \mathrm{mg}$ on Monday/Wednesday/Friday, gemcitabine $600 \mathrm{mg} / \mathrm{sqm}$, and cisplatin $12.5 \mathrm{mg} / \mathrm{sqm}$. In this latter subgroup, six patients experienced a disease stabilization and four progressed [39]. A phase I trial conducted at Mayo 
Clinic in Rochester (USA) is exploring the safety profiles of sirolimus with gemcitabine and cisplatin in patients at high risk for cholangiocarcinoma recurrence after liver transplant or surgery (NCT01888302). Trial is ongoing and estimated primary completion date is September 2016. Two phase II studies evaluating the efficacy of everolimus as monotherapy in CCA patients initiated in 2009 (NCT00973713) and in 2012 (NCT01525719). No information on the results of these two trials is yet available.

Everolimus is generally well tolerated, with most common adverse events being stomatitis, rash, fatigue, diarrhoea, nausea, and decreased appetite. A less common, life-threatening adverse event is non-infectious pneumonitis (presenting as an acute deterioration in respiratory function with ground glass-appearing or patchy opacities on computed tomography scans).

\section{Anti neoangiogenic therapies}

\subsection{Monoclonal antibodies: bevacizumab and ramucirumab}

Bevacizumab (Avastin ${ }^{\mathrm{TM}}$, Roche) is a recombinant, fully humanized iGg1 monoclonal antibody against VEGF A isoform approved for the treatment of patients with metastatic colorectal cancer, renal cell carcinoma, glioblastoma and ovarian cancer [40-43].

As far as CCA is concerned, the role of bevacizumab in combination with gemcitabine and oxaliplatin was explored in a phase II study. Study endpoint was not reached as 6-month PFS rate was 63\% (target: 70\%), whereas median PFS was 7 months, ORR 40\%, and DCR 69\% [44]. The combination of FOLFIRI (fluorouracil, folinic acid, and irinotecan) with bevacizumab as secondline treatment in patients with metastatic intrahepatic cholangiocarcinoma resulted in one complete response, four partial response, and six stable disease for an ORR of $38.4 \%$ and a DCR of $84.5 \%$. The treatment was well tolerated [45]. 
The combination of bevacizumab and erlotinib was explored as first-line treatment in 53 patients with metastatic or unresectable biliary tumors. Among the 49 evaluable patients, six (12\%) had a confirmed partial response, 25 a disease stabilization (51\%), and 18 progressed. Median OS and TTP were 9.9 and 4.4 months, respectively [46]. The same combination was furtherly tested in 102 CCA patients with refractory tumours. ORR was $6 \%$, median PFS 2.2 months and OS 4.3 months [47].

Concerning experimental studies, a multicentre phase II study of gemcitabine, capecitabine and bevacizumab as first-line treatment for locally advanced or metastatic adenocarcinoma of the gall bladder or biliary ducts recruited 50 patients in USA (NCT01007552). Study was terminated on May 2015 and results are not yet available. A phase I study aimed to evaluate safety profile of proton therapy and concurrent bevacizumab biotherapy (NCT00426829). This trial was terminated early due to low accrual and no safety data are available.

Ramucirumab (Cyramza ${ }^{\mathrm{TM}}$, Eli Lilly) is a fully human IgG1 monoclonal antibody targeting the extracellular domain of VEGFR-2. Preclinical models showed that ramucirumab might selectively bind to and inhibit the human VEGFR-2 with a much greater affinity than its natural ligand, resulting in significant antitumor activity in a wide range of malignancies [48]. Ramucirumab is approved for the treatment of NSCLC, gastric and colorectal cancer patients. A phase II trial is studying ramucirumab for advanced pre-treated biliary cancers. Recruitment of 50 patients started on December 2015 and is expected to end on December 2019 (NCT02520141).

\subsection{Multi-TKI: cediranib, regorafenib, sorafenib, sunitinib, pazopanib}

Cediranib (AstraZeneca) is a potent TKI inhibiting all three VEGF receptors (VEGFR-1, -2, -3), ckit, and platelet derived growth factor receptor alpha and beta (PDGFR- $\alpha$, PDGFR- $\beta$ ). It inhibits VEGF-induced angiogenesis showing anti-neoplastic effects in a range of tumour xenograft mouse models [49]. Cediranib has shown promising results in several phase-I clinical trials in patients with 
various solid tumours [50]. A multicentre, placebo-controlled, randomised phase II study assessed the effect on PFS of the combination of cisplatin and gemcitabine with oral cediranib $20 \mathrm{mg}$ once daily or placebo in 124 chemo-naïve patients with locally advanced or metastatic CCA. After a median follow-up of 12.2 months, median PFS was $8 \cdot 0$ months in the cediranib group and $7 \cdot 4$ months in the placebo group (HR $0.93,95 \%$ CI $0.65-1 \cdot 35 ; \mathrm{p}=0.72$ ). Patients who received cediranib had more grade $3-4$ toxic effects: hypertension $(37 \%$ vs $21 \% ; p=0.05)$, diarrhoea ( $13 \%$ vs $3 \% ; p=0 \cdot 05) ;$ and fatigue $(24 \%$ vs $11 \% ; p=0 \cdot 04)[51]$

Regorafenib (STIVARGA ${ }^{\mathrm{TM}}$, Bayer) is an oral multikinase inhibitors with activity against selected tyrosine kinases (VEGFR2-3, TIE-2, PDGFR, FGFR, RET and c-Kit) as well as a signal transduction inhibitor of the RAF/MEK/ERK pathway. It demonstrated preclinical and clinical activity in several tumours, including colorectal cancer for which treatment of refractory patients has been authorized $[52,53]$. Three phase II trials are now exploring the role of regorafenib in patients with metastatic or unresectable CCA as single agent in refractory tumours (NCT02115542), as second-line treatment (NCT02053376) or in combination with chemotherapy (GEMOX) in firstline setting (NCT02386397). Results are waited for the end of 2018. Toxicity profile of regorafenib is similar to that of other multi TKI targeting mainly VEGFR, and in particular fatigue, hypertension, and hand-foot skin reactions.

Sorafenib (NexayarTM, Bayer) is approved for the treatment of patients with hepatocarcinoma and metastatic renal cell cancer[54,55]. The activity of sorafenib as first-line treatment in patients with gatlbladder carcinomas was evaluated in a phase II trial terminated after the first stage of accrual of 25 patients as no response was recorded. Median PFS was 3 months and median OS was 9 months [56]. A Phase I/II study explored the combination of GEMOX with sorafenib in CCA patients. Due to treatment toxicity, study was terminated after completion of the phase I (9 patients enrolled) and thus no clinical information is available. Toxicities were predominantly gastrointestinal (vomiting, diarrhoea, dehydration), fever, peritoneal infection and dyspnoea. (NCT00955721). The 
concomitant administration of sorafenib and erlotinib in patients with advanced gallbladder carcinoma or CCA resulted toxic (SAE were reported in $50 \%$ of the patients including a toxic death) with poor anti-tumour activity as median PFS was 2 months and median OS 6 months (NCT 01093222).

Sunitinib (Sutent ${ }^{\mathrm{TM}}$, Pfizer) is a multi TKI mainly inhibiting VEGFR family [57] approved for the treatment of patients with GIST, metastatic renal cell carcinoma, and pancreatic neuroendocrine tumours [58-60]. A single phase II study of sunitinib as second-line treatment in patients with IH carcinomas has enrolled 51 patients in French institutions. Primary endpoint is OS and study completion date is estimated to be September 2016 (NCT01718327).

Pazopanib (Votrient ${ }^{\mathrm{TM}}$, Novartis) is approved for the treatment of patients with metastatic renal cell carcinoma and soft tissue sarcoma $[61,62]$. A phase $I I$, single-arm study is assessing the impact of pazopanib and gemcitabine on the overall response rate of 46 patients with unresectable or metastatic CCA. This study is conducted in Greece, started on June 2009 as is expected to end in November 2016 (NCT01855724). A phase I study aims to describe the safety profile of pazopanib and trametinib, a MEK inhibitor in patients with advanced solid tumours, including CCA. The study is expected to enrol a total of 111 patients. Results are awaited as study was supposed to end on April 2016 (NCT01438554). The most common toxicities of pazopanib are similar to those reported for sorafenib and sunitinib, with gastrointestinal effects (nausea, vomiting, diarrhoea) and fatigue as the most frequent side effects

\section{Anti FGFR therapy}

\subsection{BGJ398 (infigratinib)}

Preclinical studies have demonstrated that aberration in fibroblast growth factor receptor (FGFR) activity is implicated in the development and progression of CCA and other malignancies. Thus, its 
inhibition might have an important therapeutic potential as demonstrated by the pan-FGFR inhibitor BGJ398 (Infigratinib, Novartis Pharmaceuticals) either in CCA cell lines and in murine models [63]. Moreover, FGFR2 fusion events are present in up to $17 \%$ of intrahepatic CCAs and appear to predict sensitivity to FGFR inhibitors even after progression on chemotherapy [64]. On this basis, a phase II multicentre, single arm study of oral BGJ398 in patients with advanced or metastatic CCA with FGFR2 gene fusions or other FGFR genetic alterations who failed or are intolerant to platinum-based chemotherapy is ongoing. Primary endpoint is ORR and accrual of 55 patients is expected to end on July 2018 (NCT02150967).

\subsection{ARQ087}

ARQ087 (ArQule) is an orally bioavailable compound and a dual kinase inhibitor that binds to inactive form of FGFR1 and FGFR2 and potently inhibits the active form of FGFR1 and FGFR2. A phase 1/2 study evaluating the potential role of ARQ087 in patients with advanced solid tumours (including CCA) with FGFR genetic alterations is ongoing. The study is designed to explore the safety, tolerability, pharmacokinetics, pharmacodynamics, and preliminary efficacy of ARQ087 as single agent in 120 patients refractory to standard therapies and is expect to end on June 2017 (NCT01752920).

\section{Other oral inhibitors}

\subsection{ALK inhibitors}

Ceritinib (Zykadia ${ }^{\mathrm{TM}}$, Novartis) is an oral, small-molecule, ATP-competitive, tyrosine kinase inhibitor of anaplastic lymphoma kinase (ALK) approved for the treatment of ALK-positive nonsmall cell lung cancer (NSCLC) patients failing crizotinib. The potential role of ceritinib in ALKactivated gastrointestinal tumours is being explored in two phase II studies, the first including patients with ALK-activated gastrointestinal malignancies refractory to standard chemotherapies, 
the second including ROS1 and /or ALK over-expressed advanced intrahepatic or hilar CCA. (NCT02638909 and NCT02374489). Both studies started on 2015 and preliminary results are waited for the end of 2017-beginnig 2018. Ceritinib toxic effects included diarrhoea, vomiting, dehydration, elevated aminotransferase levels, and hypophosphatemia.

Another selective, ATP-competitive ALK TKI is Entrectinib (Ignyta). This small molecule is an orally bioavailable, pan-Receptor tyrosine kinases and ROS1 inhibitor. In pre-clinical models, entrectinib has shown antitumor efficacy in ALK- and ROS1-driven tumours [65]. In humans, a Phase I dose-escalation study (ALKA-372-001) in subjects with previously treated, advanced solid tumours harbouring neurotrophic receptor tyrosine kinase (NTRK)1, ROS1 or ALK alterations resulted in $22 \%$ of ORR [66]. A Phase $1 / 2$ study is assessing the role of entrectinib in subjects with previously treated, locally advanced or metastatic solid tumours including CCA with NTRK1 -2 -3, ROS1 or ALK molecular alterations (NCT02568267). This study will enrol 300 patients and is expected to end in 2018.Entrectinibis generally well tolerated, with side effects comprising asthenia, paraesthesia, nausea, myalgia, dysgeusia, vomiting, arthralgia, diarrhoea and attention disturbance.

\subsection{Anti ABL}

Bosutinib (Bosulif TM, Pfizer), a potent ATP-competitive dual Src/AblTKI, is approved for the treatment of Philadelphia chromosome-positive chronic myeloid leukaemia patients and demonstrated anti-tumour activity against several tumour xenograft [67-69]. In clinical trials, while bosutinib showed promising efficacy prolonging TTP in pre-treated patients with locally advanced or metastatic breast cancer [70], its unfavourable risk-benefit ratio and limited activity in other malignancies (including CCA) did not warrant further investigation [71,72].

Imatinib (Glivec ${ }^{\mathrm{TM}}$, Novartis) is the first TKI authorized for the treatment of patients with CML and GIST. Its impressive activity in those two malignancies led to explore its role in other tumours. A 
phase II study is testing the association of imatinib with 5-FU/leucovorin in patients with advanced carcinoma of the gallbladder and bile duct. The study has been completed in 2010 but no results have been published, yet (NCT01153750). Finally, a bicentric phase II trial of imatinib as secondline treatment in CCA patients was terminated prematurely due to poor recruitment rate and very limited efficacy [73].

\subsection{MEK inhibitors}

Trametinib (Mekinist ${ }^{\mathrm{TM}}$, GlaxoSmithKline) is a mitogen-activated, extracellular signal-regulated kinase (MEK) inhibitor 1 and 2 approved for the treatment of patients with tumours harbouring BRAF V600E or V600K gene mutations. Focusing on patients with CCA, as already mentioned, a phase I study is exploring the association of trametinib with pazopanib (see pazopanib section; NCT01438554), whereas a randomized phase II trial is aiming to assess the role of trametinib alone or in combination with chemotherapy in patients with refractory CCA (NCT02042443). The study recruited 89 participants and results are awaited for the end of 2016. The most common adverse events associated with trametinib are rash, diarrhoea, peripheral oedema, fatigue, and dermatitis.

Another oral, selective inhibitor of the MEK1/MEK2 kinases is selumetinib (Astra Zeneca) in development particularly for NSLCL tumours [74,75]. Very recently, the results of a phase I study of selumetinib with cisplatin and gemcitabine in CCA patients have been published: dose limiting toxicity (DLT) was $75 \mathrm{mg}$ twice daily, among eight evaluable patients three had a partial response and five stable disease, with a median PFS of 6.4 months [76]. Selumetinib is not currently under development in CCA patients. The most common toxicities observed were rash, mild to moderate diarrhoea, fatigue and oedema.

\subsection{PI3K inhibitors/AKT inhibitors}

Buparlisib (Novartis) is a pan-PI3K inhibitor preventing the PI3K-AKT-mTOR pathway activation [77] that demonstrated preliminary activity in preclinical models of solid tumours [78]. In clinical 
studies, some results have been reported in lymphoma and in breast cancer patients. A phase II trial in patients with various tumours (including CCA) harbouring PI3K activating mutations has been proposed in 2011, but it was closed prematurely due to lack of accrual (NCT01501604). The most common treatment-related adverse events reported were rash, increased transaminase levels, increased blood insulin levels, increased eosinophil, and hyperglycaemia.

MK2206 (Merck) is an oral pan-AKT inhibitor showing some activity in biliary cancer tumour models $[79,80]$. Promising results have been reported in clinical studies enrolling patients with breast cancer and multiple myeloma. A phase II study in refractory CCA patients treated with MK2206 as monotherapy reported two disease stabilization out of eight treated patients. Authors concluded that even though therapy was well tolerated, MK2206 alone has limited activity in this patient subset and must be eventually be tested in combination with other target agents or standard chemotherapy [81].

\subsection{Farnesyltransferase inhibitor}

Lonafarnib (Merck) is an oral selective farnesyltransferase inhibitor (FTI) [82]. In preclinical studies, lonafarnib has shown to be active against a broad spectrum of tumour cell lines and tumour xenografts in nude mice [83]. Contrasting results have been reported in patients with breast cancer, glioblastoma, head and neck cancer, and ovarian cancer. A randomised phase II trial aiming to compare lonafarnib with surgery vs surgery alone in patients with primary liver cancers including CCA was proposed in 2011. The trial has been withdrawn prior to enrolment (NCT00020774)

Another orally bioavailable non-peptidomimetic FTI is Tipifarnib (Zarnestra ${ }^{\mathrm{TM}}$, Johnson \& Johnson) which demonstrated preclinical and clinical activity against acute myeloid leukemia (AML) and breast cancer [84]. A phase I study of tipifarnib and herceptin in patients with advanced cancer including CCA enrolled 24 patients (NCT00005842). Preliminary safety results were 
presented at the Annual meeting of the American Society of Clinical Oncology (ASCO) in 2001 [85]. The most common grade 3-4 toxicities included neutropenia, nausea, and vomiting.

\subsection{Proteasome inhibitor}

The proteasome inhibitor bortezomib (Velcade ${ }^{\mathrm{TM}}$, Janssen-Cilag), demonstrated tumour cell growth suppression and apoptosis in several tumour cell lines [86]. While it has been approved for the treatment of multiple myeloma (MM) and mantle cell lymphoma (MCL) patients, bortezomib treatment in solid tumours have generally produced less promising results as it failed to demonstrate clinical activity in NSCLC, head and neck cancer, ovarian cancer, hepatocellular cancer, gastric cancer, colorectal cancer, and prostate cancer patients. A phase II trial treated patients with unresectable or metastatic gallbladder or CCA with bortezomib as single agent. A Simon two-stage design was used. The trial was discontinued early because after the first 20 patients only one unconfirmed partial response was recorded. Median TTP was 5.8 months and median OS was 9 months with 6-month and 1-year survival rates of $70 \%$ and $38 \%$, respectively. Author concluded that despite the treatment did not result in objective response, the rate of stable disease and time to progression benchmark is encouraging, so that further development of bortezomib in combination with other therapies should be considered in this setting [87]. The most frequently reported AEs were thrombocytopenia and peripheral neuropathy.

\section{Multitarget inhibitors}

Vandetanib (CAPRELSA ${ }^{\mathrm{TM}}$, AstraZeneca) is an orally available receptor TKI that inhibits EGFR, VEGFR-2, RET, BRK, Tie2, members of the EPH receptor and Src kinase families in tumour cells and endothelial cells and that demonstrated some anti-tumour activity in preclinical studies [88].

Vandetanib showed encouraging clinical activity in various tumours and it is approved for the treatment of patients with medullary thyroid cancer. Its role in CCA patients has been evaluated in 
a phase II study randomizing advanced patients to receive vandetanib $300 \mathrm{mg}$ monotherapy versus vandetanib $100 \mathrm{mg}$ plus gemcitabine versus gemcitabine plus placebo. The primary end point was PFS; secondary end points were ORR, DCR, OS and safety outcomes. A total of 173 patients were recruited at 19 centres across Italy. Median PFS were 105 days, 114 days and 148 days, respectively $(\mathrm{p}=0.18)$. No statistical difference between treatments was observed for secondary end points. Finally, the proportion of patients reporting adverse events was similar for the three groups ( $89.3 \%$ 96.6\%) [89]. The most common adverse events include diarrhoea, rash, nausea, hypertension, fatigue, abdominal pain, hypocalcaemia, hypoglycaemia, and QT prolongation. More rarely, vandetanib administration could be linked to the onset of interstitial lung disease, ischemic cerebrovascular events, serious haemorrhagic events, heart failure, hypothyroidism, hypertension, and reversible posterior leukoencephalopathy syndrome.

Merestinib (LY2801653, Lilly) inhibits MST1R, FLT3, AXL, MERTK, TEK, ROS1, DDR1/2, MKNK1/2, MET, and HGF [90,91]. A phase H study is randomizing patients with advanced CCA to receive cisplatin, gemcitabine and either ramucirumab or merestinib as first-line treatment. The primary endpoint of the trial is PFS, the main secondary endpoints OS and ORR. Enrolment of 300 patients started on May 2016 and is expected to end on April 2018 (NCT02711553). Finally, a phase $\mathrm{Ia} / \mathrm{Ib}$ study of ramucirumab in Combination With merestinib or abemaciclib in advanced cancers has been opened in April 2016 and results are waited for August 2019 (NCT02745769)

Cabozantinib (Cometriq ${ }^{\mathrm{TM}}$, Exelixis) is a TKI mainly inhibiting MET with activity against VEGFR2, RET, AXL, KIT, FLT-3 and TIE-2 kinases. Preclinical efficacy appears to be associated with its inhibitory effects against both MET and VEGFR [92]. Cabozantinib has demonstrated to be active in patients with HCC, NSCLC, metastatic castrate-resistant prostate cancer (CRPC) and metastatic medullary thyroid cancer for which this compound has been approved by regulatory agencies [93]. A phase II study administered cabozantinib as single agent in 44 pre-treated patients with locally advanced or metastatic IH or EH carcinomas. Results are expected on July 2016 
(NCT01954745). Reported toxicities of cabozantinib included fatigue, mucositis, diarrhoea, anorexia, nausea/vomiting, dysphonia, hypertension, hand-foot syndrome and increased risk of haemorrhage.

Dasatinib (SprycelTM, Bristol-Myers Squibb) is a TKI inhibiting SRC/ABL, c-KIT, and PDGFR $\alpha$ and $\beta$ [94]. In preclinical studies, it has been shown to be active against triple-negative breast cancer, gastric, pancreatic, head and neck, and lung cell lines [95,96]. Clinical studies have evaluated dasatinib activity in breast, prostate, melanoma, head and neck, and colorectal cancer patients. As far as CCA is concerned, a phase II trial of dasatinib in patients with isocitrate dehydrogenase (IDH)-mutant tumours is ongoing, primary endpoint being ORR, and main secondary endpoints being PFS and OS(NCT02428855). The study started on April 2015 and is expected to end in 2022, after having recruited 19 patients. Dasatinib was generally well-tolerated with side effects occurring in a small group of patients. Toxicities included abdominal pain, diarrhoea, nausea, vomiting, gastrointestinal bleeding, dyspepsia, pleural effusion, dyspnoea, cough, headache, peripheral neuropathy, left ventricular dysfunction, cardiac failure, cardiomyopathy, diastolic dysfunction, and QT-interval prolongation.

\section{Novel agents}

DKN-01 (Leap Therapeutics) is a humanized monoclonal antibody neutralizing Dickkopf-related protein 1 (Dkk-1) and thus inhibiting the Wnt/ $\beta$-catenin pathway [97]. This drug has shown promising activity in preclinical studies in breast, melanoma and myeloid leukemia cell lines [98100]. DKN-01 is under investigation in different clinical trials, including a phase I study designed to evaluate safety, tolerability, pharmacokinetics, and anti-tumour activity of DKN-01 in combination with gemcitabine and cisplatin in patients with CCA (NCT02375880). Preliminary safety results of the study (dose finding - Part A) have been presented at ASCO 2016 and indicated 
$300 \mathrm{mg}$ as the MTD of DKN-01, with neutropenia as the main side effect. Among the three patients receiving the MTD of DKN-01, one obtained a clinical response and two a disease stabilization [101]. Study part B (expansion cohort) is ongoing and is expected to end in September 2017, after having enrolled 32 patients.

Saracatinib (AZD0530, Astra Zeneca) is a Src-family (including Fyn, Lyn, and Src) kinases inhibitor with in vitro activity against breast, gastric, ovarian, and sarcoma cell lines as well as in mouse models of prostate cancer [102-104]. Saracatinib on CCA cell lines and in mouse models demonstrated to counteract the activation of Src and of its downstream effectors, increasing the fraction of cells in $\mathrm{G}(0)-\mathrm{G}(1)$ phase, and inhibiting cell migration, whereas at higher concentrations it inhibits CCA cell proliferation. In clinical setting, sarcatinib as single agent has been tested in patients with breast, NSCLC, colorectal, renal, gastric, pancreatic, melanoma, and head and neck cancers [105-107]. The results obtained in these studies, however, were not encouraging. Thus, sarcatinib is currently being evaluated in combination with other target agents or conventional chemotherapy. The combination of sarcatinib and cediranib has been tested in a phase I study enrolling patients with advanced, pre-treated solid tumours including CCA. All cediranib doses were tolerated; however with saracatinib $175 \mathrm{mg} /$ day, cediranib 20 or $30 \mathrm{mg}$ /day was more sustainable than $45 \mathrm{mg}$ /day. The most common adverse events were hypertension (67\%), diarrhoea (62\%), dysphonia (46\%) and fatigue (39\%). Twenty-two out of 35 evaluable patients had stable disease as the best elinical response [108].

Exerin (ADH-1, Adherex Technologies) is an N-cadherin inhibitor that demonstrated some preclinical activity against breast, melanoma, and prostate cancer cells [109-111].In the clinical setting, a phase I study is evaluating the toxicity profile and the MTD of ADH-1 in combination with gemcitabine and cisplatin in patients with unresectable or metastatic pancreatic and CCA cancers (NCT01825603). The study will enrol 24 patients and it is estimated to end in 2018 . 
Silmitasertib (CX-4945, Senhwa Biosciences) is an orally available highly selective inhibitor of CK2, a constitutively active, ubiquitous serine/threonine kinase [112]. In in vitro studies it has been demonstrated to be active against breast cancer and NSCLC [113]. Silmitasertib can be orally administered safely with some reported encouraging clinical activity as a single agent with $15 \%$ of the patients with disease stabilization lasting more than 6 months [114]. A phase I/II study is evaluating the association of silmitasertib with gemcitabine and cisplatin in the frontline treatment of patients with advanced CCA (NCT02128282). Results are waited for the first part of 2017.

Mutations in mitochondrial isocitrate dehydrogenase (IDH) were shown in preclinical studies representing a potential target for anti-tumour agents. AG 881 (Agios and Cellgene), an orally available pan-IDH mutant inhibitor has shown to fully penetrate the blood-brain barrier and to inhibit isocitrate dehydrogenase-1 (IDH1) and IDH2 mutations in cancer models. A phase I, multicentre, open-label study, aimed to assess safety, pharmacokinetic, pharmacodynamics, and clinical activity of AG-881 in patients with advanced solid tumours, including CCA, with IDH1 and/or IDH2 mutation is recruiting patients (NCT02481154). The study started on May 2015 and is expected to end in October 2018, after having enrolled 150 patients. Similarly a selective IDH1 inhibitor (AG 120) is being evaluated in patients with advanced solid tumours (including CCA) harbouring IDH1 and/or IDH2 mutation (NCT02073994). Results of this study are expected for the end of 2016.

OXY111A (NormOxyx) is a novel allosteric modulator of affinity of oxygen to haemoglobin, enhancing oxygen delivery to hypoxic tissues. OXY111A demonstrated promising results in preclinical studies of colorectal and pancreatic cancer $[115,116]$. The safety profile and the activity of OXY111Ais currently investigated in a phase IB/IIA study enrolling patients with hepatopancreato-biliary neoplasia. The trial is still recruiting patients and is expected to end on December 2016. (NCT02528526) 
PLX 8394 is an orally available, potent and selective inhibitor of BRAF V600E exhibiting promising results in melanoma resistant cells [117]. Two phase I/II studies are ongoing to evaluated the safety profile and clinical activity of the drug in refractory, advanced solid tumours, including CCA. Results a are waited for 2017 (NCT02012231 - NCT02428712).

Veliparib (ABT-888, AbbVie) is an orally bioavailable PARP-1/2 inhibitor that significantly potentiated the anti-neoplastic effect of several cytotoxic agents including temozolomide, platinum, and irinotecan in preclinical models [118,119]. In clinical studies it showed a fayourable safety profile with encouraging clinical outcomes in colorectal, breast, prostate, melanoma, NSCLC, and ovarian cancer patients [120-122]. A phase I study evaluating the efficacy and safety of veliparib, cisplatin and gemcitabine combination therapy in patients with advanced CCA, pancreatic, urothelial, or NSCLC has been terminated on February 2013, but results have never been published yet (NCT01282333). The most frequent adverse events are thrombocytopenia, anaemia, neutropenia, fatigue, nausea and vomiting.

RRx-001 (EpicentRx) is a structurally unique pharmacophore that inhibits multiple epi-enzymes and independently affects the apoptosis pathway and reactive oxygen and nitrogen species (RONS) production. RRx-001 is not cross-resistant with approved therapies and selectively targets and resensitizes hypoxic tumour cells to immunotherapy, chemotherapy and radiotherapy. Moreover, RRx-001 modulates tumour blood flow, hypoxia and vascular function triggering apoptosis in cancer cells [123]. In a phase I study, RRx-001 demonstrated encouraging antitumor activity including re-sensitization to formerly effective chemotherapy while exhibiting a benign safety profile in heavily pre-treated patients with relapsed/ refractory solid tumours [124]. CCA tumours initially responding to cisplatin and gemcitabine and then become resistant are the target population of a phase II study exploring whether therapy with RRx-001 may re-sensitize tumours to the same cisplatin and gemcitabine regimen. RRx-001 is administered intravenously weekly, for six weeks. At the end of this period, chemotherapy is introduced and in case of response, is continued as long 
as tumour respond. The primary objective of this clinical trial is to evaluate PFS at 9 weeks after the reintroduction of gemcitabine and cisplatin. A total of 30 patients will be enrolled and the study is expected to end on May 2018 (NCT02452970).

Becatecarin (Helsinn Healthcare) is a synthetic diethylaminoethyl analogue of the indolocarbazole glycoside antineoplastic antibiotic rebeccamycin. Becatecarin intercalates into DNA and stabilizes the DNA-topoisomerase I complex, thereby interfering with the topoisomerase I-catalysed DNA breakage-reunion reaction and initiating DNA cleavage and apoptosis [125] In clinical setting, becatecarin has shown promising results in colorectal, renal, and lung cancer patients as well as in CCA patients [126]. In a phase II study enrolling patients with advanced CCA it obtained an ORR of 5\% and a DCR of $40 \%$ [127]. Following these encouraging results, a randomized, phase III multicentre, open label study of becatecarin versus 5-FU plus leucovorin in 248 patients with advanced CAA was terminated on November 2006. (NCT00090025). Results have never been reported. Becatecarin was well tolerable and hematologic toxicity was the most common side effects. Non-hematologic toxicities were moderate and included weakness/fatigue, nausea/vomiting, diarrhoea and anorexia.

\section{Conclusion}

A large number of target agents have been explored in patients with locally advanced or metastatic biliary cancers (Table 3). Notwithstanding the strong biomolecular rationale and preclinical results, none of them have demonstrated a sufficient clinical activity to be authorized in the clinical routine.

Several reasons may account for these disappointing results. First of all, CCA is a rare neoplasms and thus enrolment of a large number of patients is arduous. As a consequence, it is easier to demonstrate a clinical activity of an antineoplastic compounds with a less specific mechanism of action rather than a target therapy that may be beneficial only in a selected subpopulation of 
patients. In this sense, in an unselected population multitarget TKI should be more beneficial than specific inhibitors. However, preliminary results of vandetanib did not demonstrate superiority of the drug when compared to chemotherapy. Moreover, the low number of patients prompted researchers to enrol in their studies all CCA patients, regardless of the site of the tumour. This may jeopardize results as the mutational status of intrahepatic, extrahepatic and gallbladder cancers are not similar. In a recent work presented at ASCO 2016, in fact, it has been shown that MET overexpression was detected only in intrahepatic CCA, whereas extrahepatic CCA were more frequently RAS mutated and gall bladder carcinomas were more frequently HER2 amplified [128]. Thus, any target therapy administered without a patient selection according to the biological tumour profile may results in different outcomes simply on the basis of unbalances between these three groups of tumours.

In conclusion, while waiting for novel compounds with interesting mechanisms of action, no new agent improved clinical outcome of locally advanced or metastatic CCA patients either as single agent or combined to chemotherapy. A better biological characterization of these tumours is fundamental to guide new clinical trial.

\section{Expert opinion}

Cholangiocarcinoma is a rare neoplasm harbouring complex and multiple gene mutations and/or expressions. Thus, beside the well-established role of chemotherapy several specific inhibitors have been tested. The most studied compounds are cetuximab and panitumumab. Unfortunately, these anti-EGFR monoclonal antibodies did not confirm exciting preclinical findings. One possible explanation for these disappointing results may relay on the lack of a patient selection. Making a parallelism with the scientific history of anti-EGFR antibodies in the treatment of patients with advanced colorectal cancers, first results in an unselected population were unsatisfactory. However, 
drug efficacy was dramatically improved after selection according to KRAS and then to NRAS status. In CCA patients, cetuximab was tested in patients regardless their RAS status. Some Authors tried to make a retrospective subgroup analysis, however comparison were made with very limited number of patients and thus results has to be considered as inconclusive. Panitumumab was tested in patients with KRAS wild type tumours. Notwithstanding this patient selection, results were negative. It is a good matter of debate wondering whether these disappointing findings would have been comparable in a RAS wild type population. Another possible explanation could be the choice of the biomolecular marker. It has been recently published a comprehensive review in which EGFR expression has been identified as a prognostic parameter [129]. This finding is very interesting as it gives rise to an intriguing question: should we continue to stratified CCA patients according to the RAS status or should we group patients according to EGFR expression? And in this latter case, which could be the positivity threshold? Future researches should be directed in defining predictive indicators for anti-EGFR therapies.

Beside some positive findings obtained with anti-EGFR therapy, no striking results are waited for the novel therapies currently tested and summarized in Table 3. No clinically relevant outcomes have been described for anti-HER2, anti-VEGF, anti-ABL agents and mTor inhibitors. Continuing the parallelism with colorectal cancer, some promising preliminary activity could be waited for the multitarget TKIs such as regorafenib, cabozantinib, merestinib, and dasatinib. In fact, while specific inhibitors (for instance anti-EGFR and anti-VEGF) had to be combined with chemotherapy, these multitarget compounds demonstrated to be active when administered as single agents. Finally, despite interesting mechanisms of action, no outstanding results are waited for the novel compounds listed at the end of Table 3.

In this rare neoplasm the future challenge is the discovery of biomolecular alterations which drive tumour progression and aggressiveness in order to focus on selected patients avoiding resource consuming and wasting. In this sense, next-generation sequencing (NGS) survey of biliary tract 
cancers may help in determining which is the leading mutation of each single tumour, permitting physician to personalize therapy in the very next future. Some correlations between NGS and clinical outcome have already been reported [130]. The limitation of this techniques is mainly the cost. However, the standardization of a panel of genetic alteration automatically detected may reduce costs permitting to a larger spectrum of tumours to be analysed [131]. Some exciting data are already available for NSCLC patients [132]. This technique will also facilitate the description of possible multiple mutations driving tumour progression requiring various specific inhibitions and, maybe, the mechanisms of acquired drug resistance.

The main limitation of patient selection according to relative rare gene mutations is that accrual of a particular population of CCA patients is somehow impossible without the involvement of a large number of institutions. As a consequence, when designing a new trial researchers must choose whether collaborate with a large number of institutions (thing often difficult and expensive in practice) or enrol unselected patients (easier in practice). Testing a new compound in an unselected population, however, could result in negative results even if a particular agent is very active in a particular subgroup of patients. Thus, it could be hypothesized that some novel therapies already explored in unselected patients and considered as ineffective could be very active in selected ones. This was the case, for instance, for gefitinib in EGFR mutated adenocarcinoma of the lung. Thus, even though international collaborations are difficult, this will be the best way to explore particular gene inhibition Some trials have been designed in this sense, aiming to explore the clinical usefulness of specific inhibitors in selected patients (such as those with tumours harbouring ALK, ROS1, FGFR, NTRK, and IDH genetic alterations). Although many of these studies will screen a large population to enrol a relative small number of patients, their results will be very interesting and will pave the way for new stimulating clinical trials. 
Finally, immunotherapy has gain extreme importance in the last few years, especially in patients bearing metastatic melanoma, renal cell carcinoma and other several solid tumours. It will be of great interest to explore whether this class of agents may be beneficial also in patients with CCA.

\section{Funding}

This paper was not funded.

\section{Declaration of interest}

M. Tampellini has received grants from Eli Lilly, Bayer Plc and Sanofi. G. V. Scagliotti has received grants from Eli Lilly and Roche. The authors have no other relevant affiliations or financial involvement with any organization or entity with a financial interest in or financial conflict with the subject matter or materials discussed in the manuscript apart from those disclosed. 


\section{Bibliography}

Papers of special note have been highlighted as either of interest $(\bullet)$ or of considerable interest (••) to readers.

1. Razumilava N, Gores GJ. Cholangiocarcinoma. Lancet. 2014;383(9935):2168-2179.

\section{•• Comprehensive review on Cholangiocarcinoma}

2. Alvaro D, Crocetti E, Ferretti S, et al. Descriptive epidemiology of cholangiocarcinoma in Italy. Dig Liver Dis. 2010;42(7):490-495.

3. Valle J, Wasan H, Palmer DH, et al. ABC-02 Trial Investigators. Cisplatin plus gemcitabine versus gemcitabine for biliary tract cancer. N Engl J Med. 2010;362(14):1273-1281.

- Study that established the standard of care of locally advanced or metastatic cholangiocarcinomas.

4. Pignochino Y, Sarotto I, Peraldo-Neia C, et al. Targeting EGFR/HER2 pathways enhances the antiproliferative effect of gemcitabine in biliary tract and gallbladder carcinomas. BMC Cancer. 2010;(10):631.

5. Bokemeyer C, Van Cutsem E, Rougier P, et al. Addition of cetuximab tochemotherapy as first-line treatment for KRAS wild-type metastatic colorectal cancer: pooled analysis of the CRYSTAL and OPUS randomised clinical trials. Eur J Cancer. 2012;48(10):1466-1475.

6. Ye LC, Liu TS, Ren L, et al. Randomized controlled trial of cetuximab plus chemotherapy for patients with KRAS wild-type unresectable colorectal liver-limited metastases. J Clin Oncol 2013;31(16):1931-1938. 
7. Bonner JA, Harari PM, Giralt J, et al. Radiotherapy plus cetuximab for locoregionally advanced head and neck cancer: 5-year survival data from a phase 3 randomised trial, and relation between cetuximab-induced rash and survival. Lancet Oncol. 2010;11(1):21-28.

8. Chang PY, Cheng MF, Lee HS, et al. Preliminary experience of cetuximab in the treatment of advanced-stage biliary tract cancer. Onkologie. 2010;33(1-2):45-47.

9. Borbath I, Ceratti A, Verslype C, et al. Combination of gemcitabine and cetuximab in patients with advanced cholangiocarcinoma: a phase II study of the Belgian Group of Digestive Oncology. Combination of gemcitabine and cetuximab in patients with advanced cholangiocarcinoma: a phase II study of the Belgian Group of Digestive Oncology. Ann Oncol. 2013;24(11):2824-2829.

10. Malka D, Cervera P, Foulon S, et al. Gemcitabine and oxaliplatin with or without cetuximab in advanced biliary-tract cancer (BINGO): a randomised, open-label, non-comparative phase 2 trial. BINGO investigators. Lancet Oncol. 2014;15(8):819-828.

- Study that describes an active chemotherapeutic regimen in locally advanced or metastatic cholangiocarcinomas.

11. Paule B, Herelle MO, Rage E, et al. Cetuximab plus gemcitabine-oxaliplatin (GEMOX) in patients with refractory advanced intrahepatic cholangiocarcinomas. Oncology. 2007;72(1-2):105110.

12. Gruenberger B, Schueller J, Heubrandtner U, et al. Cetuximab, gemcitabine, and oxaliplatin in patients with unresectable advanced or metastatic biliary tract cancer: a phase 2 study. Lancet Oncol. 2010;11(12):1142-1148. 
13. Chen JS, Hsu C, Chiang NJ, et al. A KRAS mutation status-stratified randomized phase II trial of gemcitabine and oxaliplatin alone or in combination with cetuximab in advanced biliary tract cancer. Ann Oncol. 2015;26(5):943-949.

\section{- KRAS mutation is not an indicator of cetuximab activity in advanced biliary tract cancers.}

14. Douillard JY, Siena S, Cassidy J, et al. Results from PRIME: randomized phase III study of panitumumab with FOLFOX4 for first-line treatment of metastatic colorectal cancer Ann Oncol. 2014;25(7):1346-1355.

15. Jensen LH, Lindebjerg J, Ploen J, et al. Phase II marker-driven trial of panitumumab and chemotherapy in KRAS wild-type biliary tract cancer. Ann Oncol. 2012;23(9):2341-2346.

16. Hezel AF, Noel MS, Allen JN, et al. Phase II study of gemcitabine, oxaliplatin in combination with panitumumab in KRAS wild-type unresectable or metastatic biliary tract and gallbladder cancer. Br J Cancer. 2014;111(3):430-436.

17. Sohal DP, Mykulowycz K, Uehara T, et al. A phase II trial of gemcitabine, irinotecan and panitumumab in advanced chølangiocarcinoma. Ann Oncol. 2013;24(12):3061-3065.

18. Leone F, Marino D, Cereda S, et al. Panitumumab in combination with gemcitabine and oxaliplatin does not prolong survival in wild-type KRAS advanced biliary tract cancer: A randomized phase 2 trial (Vecti-BIL study). Cancer. 2016;122(4):574-581.

\section{- Lack of efficacy of panitumumab in KRAS wild type advanced biliary tract cancers.}

19. Wu YL, Zhou C, Liam CK, et al. First-line erlotinib versus gemcitabine/cisplatin in patients with advanced EGFR mutation-positive non-small-cell lung cancer: analyses from the phase III, randomized, open-label, ENSURE study. Ann Oncol. 2015;26(9):1883-1889.

20. Philip PA, Mahoney MR, Allmer C, et al. Phase II study of erlotinib in patients with advanced biliary cancer. J Clin Oncol. 2006;24(19):3069-3074. 
21. Lee J, Park SH, Chang HM, et al. Gemcitabine and oxaliplatin with or without erlotinib in advanced biliary-tract cancer: a multicentre, open-label, randomised, phase 3 study. Lancet Oncol. 2012;13(2):181-188.

22. Lubner SJ, Mahoney MR, Kolesar JL, et al. Report of a multicenter phase II trial testing a combination of biweekly bevacizumab and daily erlotinib in patients with unresectable biliary cancer: a phase II Consortium study. J Clin Oncol. 2010;28(21):3491-3497.

23. Schramm A, De Gregorio N, Widschwendter P, et al. Targeted Therapies in HER2-Positive Breast Cancer - a Systematic Review. Breast Care (Basel). 2015;10(3):173-178.

24. Pectasides E. Genomic Alterations and Targeted Therapy in Gastric and Esophageal Adenocarcinoma. Clin Ther. 2016;pii:S0149-2918(16):30153-30159.

25. Yoshikawa D, Ojima H, Iwasaki M, et al. Clinicopathological and prognostic significance of EGFR, VEGF, and HER2 expression in cholangiocarcinoma. Br J Cancer. 2008;98(2):418-425.

26. Andersen JB, Spee B, Blechacz BR, et al. Genomic and genetic characterization of cholangiocarcinoma identifies therapeutic targets for tyrosine kinase inhibitors. Gastroenterology. 2012;142(4):1021-1031.

27. Law LY. Dramatic response to trastuzumab and paclitaxel in a patient with human epidermal growth factor receptor 2-positive metastatic cholangiocarcinoma. J Clin Oncol. 2012; 30(27):e 271-273.

28. Sorscher S. Marked radiographic response of a HER-2-overexpressing biliary cancer to trastuzumab. Cancer Manag Res. 2013;11(9):1-3.

29. Javle M, Churi C, Kang HC, et al. HER2/neu-directed therapy for biliary tract cancer. J Hematol Oncol. 2015;29(8):58. 
30. Peck J, Wei L, Zalupski M, et al. HER2/neu may not be an interesting target in biliary cancers: results of an early phase II study with lapatinib. Oncology. 2012;82(3):175-179.

31. Ramanathan RK, Belani CP, Singh DA, et al. A phase II study of lapatinib in patients with advanced biliary tree and hepatocellular cancer. Cancer Chemother Pharmacol. 2009;64(4):777783.

32. Chung JY, Hong SM, Choi BY, et al. The expression of phospho-AKT, phosphomTOR, and PTEN in extrahepatic cholangiocarcinoma. Clin Cancer Res. 2009;15(2):660-667.

33. Wu Q, Kiguchi K, Kawamoto $\mathrm{T}$, et al. Therapeutic effect of rapamycin on gallbladder cancer in a transgenic mouse model. Cancer Res. 2007;67(8):3794-3800.

34. Baselga J, Campone M, Piccart M, et al. Everolimus in postmenopausal hormone-receptorpositive advanced breast cancer. N Engl J Med. 2012;366(6):520-529.

-• Study demonstrating the efficacy of everolimus in hormone-receptor positive advanced breast cancer.

35. Chambers J, Reed N, Mansoor W, et al. A phase-3 randomized trial of everolimus (RAD001) vs. placebo in advanced pancreatic NET (RADIANT-3). Regul Pept. 2010;164(1):6-7.

36. Yao JC, Fazio N, Singh S, et al. Everolimus for the treatment of advanced, non-functional neuroendocrine tumours of the lung or gastrointestinal tract (RADIANT-4): a randomised, placebocontrolled, phase 3 study. Lancet. 2016;387(10022):968-977.

\section{- Efficacy of everolimus in neuroendocrine tumours of the lung or gastrointestinal tract.}

37. Motzer RJ, Escudier B, Oudard S, et al. Phase 3 trial of everolimus for metastatic renal cell carcinoma : final results and analysis of prognostic factors. Cancer. 2010; 116(18):4256-4265. 
38. Buzzoni R, Pusceddu S, Bajetta E, et al. Activity and safety of RAD001 (everolimus) in patients affected by biliary tract cancer progressing after prior chemotherapy: a phase II ITMO study. Ann Oncol. 2014;25(8):1597-1603.

39. Costello BA, Borad MJ, Qi Y, et al. Phase I trial of everolimus, gemcitabine and cisplatin in patients with solid tumors. Invest New Drugs. 2014;32(4):710-716.

40. Pavlidis ET, Pavlidis TE. Role of bevacizumab in colorectal cancer growth and its adverse effects: a review. World J Gastroenterol. 2013;19(31):5051-5060.

41. Fischer S, Gillessen S, Rothermundt C. Sequence of treatment in locally advanced and metastatic renal cell carcinoma. Transl Androl Urol. 2015;4(3):310-325.

42. Mallick S, Gandhi AK, Rath GK. Therapeutic approach beyond conventional temozolomide for newly diagnosed glioblastoma: Review of the present evidence and future direction. Indian $\mathbf{J}$ Med Paediatr Oncol. 2015;36(4):229-237.

43. McClung EC, Wenham RM. Profile of bevacizumab in the treatment of platinum-resistant ovarian cancer: current perspectives. Int J Womens Health. 2016;15(8):59-75.

44. Zhu AX, Meyerhardt JA, Blaszkowsky LS, et al. Efficacy and safety of gemcitabine, oxaliplatin, and bevacizumab in advanced biliary-tract cancers and correlation of changes in 18fluorodeoxyglucose PET with clinical outcome: a phase 2 study. Lancet Oncol. 2010;11(1):48-54.

45. Guion-Dusserre JF, Lorgis V, Vincent J, et al. FOLFIRI plus bevacizumab as a second-line therapy for metastatic intrahepatic cholangiocarcinoma. World J Gastroenterol. 2015;21(7):20962101.

46. Lubner SJ, Mahoney MR, Kolesar JL et al. Report of a multicenter phase II trial testing a combination of biweekly bevacizumab and daily erlotinib in patients with unresectable biliary cancer: a phase II Consortium study. J Clin Oncol. 2010;28(21):3491-3497. 
47. Rohrberg KS, Olesen RK, Pfeiffer P, et al. Phase II trial of erlotinib and bevacizumab in patients with advanced upper gastrointestinal cancers. ActaOncol. 2012;51(2):234-242.

48. Aprile G, Rijavec E, Fontanella C, et al. Ramucirumab: preclinical research and clinical development. Onco Targets Ther. 2014;29(7):1997-2006.

49. Wedge SR, Kendrew J, Hennequin LF, et al. AZD2171: a highly potent, orally bioavailable, vascular endothelial growth factor receptor-2 tyrosine kinase inhibitor for the treatment of cancer. Cancer Res. 2005;65(10):4389-4400.

50. Drevs J, Siegert P, Medinger M, et al. Phase I clinical study of AZD2171, an oral vascular endothelial growth factor signaling inhibitor, in patients with advanced solid tumors. Clin Oncol. 2007;25(21):3045-3054.

51. Valle JW, Wasan H, Lopes A, Backen AC, et al. Cediranib or placebo in combination with cisplatin and gemcitabine chemotherapy for patients with advanced biliary tract cancer (ABC-03): a randomised phase 2 trial. Lancet Oncol. 2015;16(8):967-978.

52. Strumberg D, Scheulen ME, Schultheis B, et al. Regorafenib (BAY 73-4506) in advanced colorectal cancer: a phase I study. Br J Cancer. 2012;106(11):1722-1727.

53. Grothey A, Van Cutsem E, Sobrero A, et al. CORRECT Study Group. Regorafenib monotherapy for preyiously treated metastatic colorectal cancer (CORRECT): an international, multicentre, randomised, placebo-controlled, phase 3 trial. Lancet. 2013;381(9863):303-312.

\section{Regorafenib is active in previously treated metastatic colorectal cancer patients.}

54. Schlachterman A, Craft WW Jr, Hilgenfeldt E, et al. Current and future treatments for hepatocellular carcinoma. World J Gastroenterol. 2015;21(28):8478-8491. 
55. FishmanMN, Tomshine J, Fulp WJ, et al. A systematic review of the efficacy and safety experience reported for sorafenib in advanced renal cell carcinoma (RCC) in the post-approval setting. PLoS One. 2015;10(4):e0120877.

56. El-Koueiry AB, Rankin CJ, Ben-Josef E, et al. SWOG 0514: a phase II study of sorafenib in patients with unresectable or metastatic gallbladder carcinoma and cholangiocarcinoma. Invest New Drugs. 2012;30(4):1646-1651.

57. Carlisle B, Demko N, Freeman G,et al. Benefit, Risk, and Outcomes in Drug Development: A Systematic Review of Sunitinib. J Natl Cancer Inst. 2015;108(1)pii: djv292.

\section{•- A comprehensive review on Sunitinib}

58. Abdel-Rahman O, Fouad M. Systemic therapy options for advanced gastrointestinal stromal tumors beyond first-line imatinib: a systematic review. Future Oncol. 2015;11(12):1829-1843.

59. Larkin J, Paine A, Foley G, et al. First-line treatment in the management of advanced renal cell carcinoma: systematic review/and network meta-analysis. Expert Opin Pharmacother. 2015;16(13):1915-1927.

60. Raymond E, Dahan L, Raoul JL, et al. Sunitinib malate for the treatment of pancreatic neuroendocrine tumors. N Engl J Med. 2011;364(6):501-513.

61. Cella D, Beaumont JL. Pazopanib in the treatment of advanced renal cell carcinoma. Ther Adv Urol. 2016;8(1):61-69.

62. Sleijfer S, Ray-Coquard I, Papai Z, et al. Pazopanib, a multikinase angiogenesis inhibitor, in patients with relapsed or refractory advanced soft tissue sarcoma: A phase II study from the European Organisation for Research and Treatment of Cancer Soft Tissue and Bone Sarcoma Group (EORTC study 62043). J Clin Oncol. 2009;27(19):3126-3132. 
63. Rizvi S, Yamada D, Hirsova P, et al. A Hippo and Fibroblast Growth Factor Receptor Autocrine Pathway in Cholangiocarcinoma. J Biol Chem. 2016;291(15):8031-8047.

64. Ang C. Role of the fibroblast growth factor receptor axis in cholangiocarcinoma. J Gastroenterol Hepatol. 2015;30(7):1116-1122.

65. Ardini E, Menichincheri M, Banfi P, et al. The ALK inhibitor NMS-E628 also potentially inhibits ROS1 and induces tumor regression in ROS-driven models [abstract]. In. Annual meeting of the American association for cancer research; Apr 6-10; Washington, DC. Philadelphia (PA): American Association for Cancer Research (AACR). Cancer Res. 2013;73(8 Suppl; abstract nr 2092).

66. De Braud FG, Niger M, Damian S, et al. Alka-372-001: first-in-human, phase I study of entrectinib - an oral pan-trk, ROS1, and ALK inhibitor - in patients with advanced solid tumors with relevant molecular alterations. J Clin Oncol. 2015;33(suppl; abstr 2517).

67. Messersmith WA, Rajeshkumar NV, Tan AC, et al. Efficacy and pharmacodynamic effects of bosutinib (SKI-606), a Src/Abl inhibitor, in freshly generated human pancreas cancer xenografts. Mol Cancer Ther. 2009;8(6):1484-1493.

68. Vultur A, Buettner R, Kowolik C, et al. SKI-606 (bosutinib), a novel Src kinase inhibitor, suppresses migration and invasion of human breast cancer cells. Mol Cancer Ther. 2008;7(5):11851194.

69. Rabbani SA, Valentino ML, Arakelian A, et al. SKI-606 (Bosutinib) blocks prostate cancer invasion, growth, and metastasis in vitro and in vivo through regulation of genes involved in cancer growth and skeletal metastasis. F. Mol Cancer Ther. 2010;9(5):1147-1157. 
70. Campone M, Bondarenko I, Brincat S, et al. Phase II study of single-agent bosutinib, a $\mathrm{Src} / \mathrm{Abl}$ tyrosine kinase inhibitor, in patients with locally advanced or metastatic breast cancer pretreated with chemotherapy. Ann Oncol. 2012;23(3):610-617.

71. Isakoff SJ, Wang D, Campone M, et al. Bosutinib plus capecitabine for selected advanced solid tumours: results of a phase 1 dose-escalation study. Br J Cancer. 2014;111(11):2058-2066.

72. Moy B, Neven P, Lebrun F, et al. Bosutinib in combination with the aromatase inhibitor letrozole: a phase II trial in postmenopausal women evaluating first-line endocrine therapy in locally advanced or metastatic hormone receptor-positive/HER2-negative breast cancer. Oncologist. 2014;19(4):348-349.

73. Roth A, Schleyer E, Schoppmeyer K, et al. Imatinib mesylate for palliative second-line treatment of advanced biliary tract cancer: a bicentric phase II study. Onkologie. 2011;34(8-9):469470.

74. Davies BR, Logie A, McKay JS, et al. AZD6244 (ARRY-142886), a potent inhibitor of mitogen-activated protein kinase/extracellular signal-regulated kinase kinase $1 / 2$ kinases: mechanism of action in vivo, pharmacokinetic/pharmacodynamic relationship, and potential for combination in preclinical models. Mol Cancer Ther. 2007;6(8):2209-2219.

75. Hainsworth JD, Cebotaru CL, Kanarev V, et al. A phase II, open-label, randomized study to assess the efficacy and safety of AZD6244 (ARRY-142886) versus pemetrexed in patients with non-small cell lung cancer who have failed one or two prior chemotherapeutic regimens. J Thorac Oncol. 2010;5(10):1630-1636.

76. Bridgewater J, Lopes A, Beare S, et al. A phase 1b study of Selumetinib in combination with Cisplatin and Gemcitabine in advanced or metastatic biliary tract cancer: the ABC-04 study. BMC Cancer. 2016;16(1):153. 
77. Dienstmann R, Rodon J, Serra V, et al. Picking the point of inhibition: a comparative review of PI3K/AKT/mTOR pathway inhibitors. J Mol Cancer Ther. 2014;13(5):1021-1031.

78. Maira SM, Pecchi S, Huang A, et al. Identification and characterization of NVP-BKM120, an orally available pan-class I PI3-kinase inhibitor. Mol Cancer Ther. 2012;11(2):317-328.

79. Altomare DA, Testa JR. Perturbations of the AKT signaling pathway in human cancer. Oncogene. 2005;24(50):7455-7464.

80. Leal P, Garcia P, Sandoval A, et al. AKT/mTOR substrate P70S6K is frequently phosphorylated in gallbladder cancer tissue and cell lines. Onco Targets Ther. 2013;6:1373-1384.

81. Ahn DH, Li J, Wei L, et al. Results of an abbreviated phase-H study with the Akt Inhibitor MK-2206 in Patients with Advanced Biliary Cancer. Sci Rep. 2015,5:12122.

82. Sebti SM, Hamilton AD, editors. Farnesyltransferase Inhibitors in Cancer Therapy. Totowa, NJ: Humana Press; 2001.

83. Nielsen LL, Shi B, Hajian G, et al. Combination therapy with the farnesyl protein transferase inhibitor SCH66336 and SCH58500 (p53 adenovirus) in preclinical cancer models. Cancer Res. 1999;59(23):5896-5901.

84. Li T, Guo M, Gradishar WJ, et al. A phase II trial of capecitabine in combination with the farnesyltransferase inhibitor tipifarnib in patients with anthracycline-treated and taxane-resistant metastatic breast cancer: an Eastern Cooperative Oncology Group Study (E1103). Breast Cancer Res Treat. 2012;134(1):345-352.

85. Schwartz G, Rowinsky EK, Rha SY, et al. A phase I, pharmacokinetic, and biologic correlative study of R115777 and trastuzumab (herceptin) in patients with advanced cancer. [Abstract] Proceedings of the American Society of Clinical Oncology 20:A-322, 2001. 
86. Johnson DE. The ubiquitin-proteasome system: opportunities for therapeutic intervention in solid tumors. Endocr Relat Cancer. 2015;22(1):T1-17.

87. Denlinger CS, Meropol NJ, Li T, et al. A phase II trial of the proteasome inhibitor bortezomib in patients with advanced biliary tract cancers. Clin Colorectal Cancer. 2014;13(2):8186.

88. Carlomagno F, Vitagliano D, Guida T, et al. ZD6474, an orally available inhibitor of KDR tyrosine kinase activity, efficiently blocks oncogenic RET kinases. Cancer Res. 2002;62(24):72847290.

89. Santoro A, Gebbia V, Pressiani T, et al. A randomized, multicenter, phase II study of vandetanib monotherapy versus vandetanib in combination with gemcitabine versus gemcitabine plus placebo in subjects with advanced biliary tract cancer: the VanGogh study. Ann Oncol. 2015;26(3):542-547.

90. Christensen JG, Burrows J, Salgia R. c-Met as a target for human cancer and characterization of inhibitors for therapeutic intervention. Cancer Lett. 2005;225(1):1-26.

91. Yakes FM, Chen J, Tan J, et al. Cabozantinib (XL184), a novel MET and VEGFR2 inhibitor, simultaneously suppresses metastasis, angiogenesis, and tumor growth. Mol Cancer Ther. $2011 ; 10(12): 2298-2308$.

92. Yan SB, Peek VL, Ajamie R, et al. LY2801653 is an orally bioavailable multi-kinase inhibitor with potent activity against MET, MST1R, and other oncoproteins, and displays antitumor activities in mouse xenograft models. Invest New Drugs. 2013;31(4):833-844.

93. Weitzman SP, Cabanillas ME. The treatment landscape in thyroid cancer: a focus on cabozantinib. Cancer Manag Res. 2015;7:265-278. 
94. Lindauer M, Hochhaus A. Dasatinib. Recent Results Cancer Res. 2014;201:27-65.

95. Montero JC, Seoane S, Ocaña A, et al. Inhibition of SRC family kinases and receptor tyrosine kinases by dasatinib: possible combinations in solid tumors. Clin Cancer Res. 2011;17(17):5546-5552.

96. Park SI, Zhang J, Phillips KA, et al. Targeting SRC family kinases inhibits growth and lymph node metastases of prostate cancer in an orthotopic nude mouse model. Cancer Res. 2008;68(9):3323-3333.

97. Veeck J, Dahl E. Targeting the Wnt pathway in cancer: the emerging role of Dickkopf-3. Biochim Biophys Acta. 2012;1825(1):18-28.

98. Chen J1, Li H, Chen H, et al. Dickkopf-1 inhibits the invasive activity of melanoma cells. Clin Exp Dermatol. 2012;37(4):404-410.

99. Liu FZ, He L, Wang JS, et al. Effect of Decitabine on DKK1 Gene Demethylation in Leukemia Cells. Zhongguo Shi Yan Xue Ye Xue Za Zhi. 2016;24(1):56-60.

100. Rachner TD, Göbel A, Thiele S, et al. Dickkopf-1 is regulated by the mevalonate pathway in breast cancer. Breast Cancer Res. 2014;16(1):R20.

101. Eads JR, Goyal L, Stein S, et al. Phase I study of DKN-01, an anti-DKK1 antibody, in combination with gemcitabine $(\mathrm{G})$ and cisplatin $(\mathrm{C})$ in patients (pts) with advanced biliary cancer. $\mathrm{J}$ Clin Oncol. 2016;34(suppl; abstr e15603).

102. Green TP, Fennell M, Whittaker R, et al. Preclinical anticancer activity of the potent, oral Src inhibitor AZD0530. Mol Oncol. 2009; 3(3):248-261.

103. Wang L, Yu X, Dong J, et al. Combined SRC inhibitor saracatinib and anti-ErbB2 antibody H2-18 produces a synergistic antitumor effect on trastuzumab-resistant breast cancer. Biochem Biophys Res Commun. 2016;pii:S0006-291X(16)31578-31579. 
104. Jain S, Wang X, Chang CC, et al. Src Inhibition Blocks c-Myc Translation and Glucose Metabolism to Prevent the Development of Breast Cancer. Cancer Res. 2015;75(22):4863-4875.

105. Baselga J, Cervantes A, Martinelli E, et al. Phase I safety, pharmacokinetics, and inhibition of SRC activity study of saracatinib in patients with solid tumors. Clin Cancer Res. 2010;16(19):4876-4883.

106. Reddy SM, Kopetz S, Morris J, et al. Phase II study of saracatinib (AZD0530) in patients with previously treated metastatic colorectal cancer. Invest New Drugs. 2015;33(4):977-984.

107. Gubens MA, Burns M, Perkins SM, et al. A phase II study of saracatinib (AZD0530), a Src inhibitor, administered orally daily to patients with advanced thymic malignancies. Lung Cancer. 2015;89(1):57-60.

108. Trarbach T, Schultheis B, Gauler TC, et al. Phase Iopen-label study of cediranib, an oral inhibitor of VEGF signalling, in combination with the oral Src inhibitor saracatinib in patients with advanced solid tumours. Invest New Drugs. 2012;30(5):1962-1971.

109. Rieger-Christ KM, Lee P, Zagha R, et al. Novel expression of N-cadherin elicits in vitro bladder cell invasion via the akt signalling pathway. Oncogene. 2004;23(27):4745-4753.

110. Li G, Satyamoorthy K, Herlyn M. N-cadherin-mediated intercellular interactions promote survival and migration of melanoma cells. Cancer Res. 2001;61(9):3819-3825.

111. Li H, Price DK, Figg WD. ADH1, an N-cadherin inhibitor, evaluated in preclinical models of angiogenesis and androgen-independent prostate cancer. Anticancer Drugs. 2007;18(5):563-568.

112. Ruzzene M, Pinna LA. Addiction to protein kinase CK2: a common denominator of diverse cancer cells? Biochim Biophys Acta. 2010;1804(3):499-504. 
113. Pierre F, Chua PC, O'Brien SE, et al. Discovery and SAR of 5-(3chlorophenylamino)benzo[c][2,6]naphthyridine-8-carboxylic acid (CX-4945), the first clinical stage inhibitor of protein kinase CK2 for the treatment of cancer. Med Chem. 2011;54(2):635-654.

114. Marschke RF, Borad MJ, McFarland RW, et al. Findings from the Phase I clinical trials of CX-4945, an orally available inhibitor of CK2. J Clin Oncol. 2011;29(suppl; abstr 3087).

115. Derbal-Wolfrom L, Pencreach E, Saandi T, et al. Increasing the oxygen load by treatment with myo-inositol trispyrophosphate reduces growth of colon cancer and modulates the intestine homeobox gene Cdx2. Oncogene. 2013;32(36):4313-4318.

116. Raykov Z, Grekova SP, Bour G, et al. Myo-inositol trispyrophosphate-mediated hypoxia reversion controls pancreatic cancer in rodents and enhances gemcitabine efficacy. Int J Cancer. $2014 ; 134(11): 2572-2582$.

117. Basile KJ, Le K, Hartsough EJ, et al. Inhibition of mutant BRAF splice variant signaling by next-generation, selective RAF inhibitors. Pigment Cell Melanoma Res. 2014;27(3):479-484.

118. Nowsheen S, Bonner JA, Yang ES. The poly(ADP-Ribose) polymerase inhibitor ABT-888 reduces radiation-induced nuclear EGFR and augments head and neck tumor response to radiotherapy. Radiother Oncol. 2011;99(3):331-338.

119. Ávila-Arroyo S, Nuñez GS, García-Fernández LF, Galmarini CM. Synergistic Effect of Trabectedin and Olaparib Combination Regimen in Breast Cancer Cell Lines. J Breast Cancer. 2015;18(4):329-338.

120. Middleton MR, Friedlander P, Hamid O, et al. Randomized phase II study evaluating veliparib (ABT-888) with temozolomide in patients with metastatic melanoma. Ann Oncol. 2015;26(10):2173-2179. 
121. Hussain M, Carducci MA, Slovin S,et al. Targeting DNA repair with combination veliparib (ABT-888) and temozolomide in patients with metastatic castration-resistant prostate cancer. Invest New Drugs. 2014;32(5):904-912.

122. Pishvaian MJ, Slack R, Witkiewicz A, et al. A phase II study of the PARP inhibitor ABT888 plus temozolomide in patients with heavily pretreated, metastatic colorectal cancer. J Clin Oncol. 2011;29(suppl; abstr 3502).

123. Zhao H, Ning S, Scicinski J, et al. Epigenetic effects of RRx-001: a possible unifying mechanism of anticancer activity. Oncotarget. 2015;6(41):43172-43181.

124. Reid T, Oronsky B, Scicinski J, et al. Safety and activity of RRx-001 in patients with advanced cancer: a first-in-human, open-label, dose-escalation phase 1 study. Lancet Oncol. 2015;16(9):1133-1142.

125. Weitman S, Moore R, Barrera H. et al. In vitro antitumor activity of rebeccamycin analog (NSC\# 655649) against pediatric solid tumors. J Pediatr Hematol Oncol. 1998;20(2):136-9.

126. Dowlati A, Hoppel CL, Ingalls ST, et al. Phase I clinical and pharmacokinetic study of rebeccamycin analog NSC 655649 given daily for five consecutive days. J Clin Oncol. 2001;19(8):2309-2318,

127. Dowlati A, Posey J, Ramanathan RK, et al. Phase II and pharmacokinetic trial of rebeccamycin analog in advanced biliary cancers. Cancer Chemother Pharmacol. 2009;65(1):73-78.

128. Sauri T, Macarulla T, Cabrera G, et al. Comprehensive profiling of biliary tract cancers (BTC) to reveal molecular heterogeneity with implications for matched targeted therapies (MTT). J Clin Oncol 2016;34(suppl; abstr 4085). 
129. Ruys AT, Groot Koerkamp B, Wiggers JK, et al. Prognostic biomarkers in patients with resected cholangiocarcinoma: a systematic review and meta-analysis. Ann Surg Oncol. 2014;21(2):487-500.

130. Ahn DH, Javle MM, Ahn C, et al. Next-generation sequencing (NGS) survey of biliary tract cancer (BTC) to reveal the association between tumor somatic variants and chemotherapy resistance. J Clin Oncol. 2016;34(suppl; abstr 4079).

131. Frampton GM, Fichtenholtz A, Otto GA, et al. Development and validation of a clinical cancer genomic profiling test based on massively parallel DNA sequencing. Nat Biotechnol. 2013;31(11):1023-1031.

132. Drilon A, Wang L, Arcila ME,et al. Broad, Hybrid Capture-Based Next-Generation Sequencing Identifies Actionable Genomic Alterations in Lung Adenocarcinomas Otherwise Negative for Such Alterations by Other Genomic Testing Approaches. Clin Cancer Res. 2015;21(16):3631-3639. 
Table 1. Key results of trials exploring cetuximab in locally advanced or metastatic CCA patients

\begin{tabular}{|c|c|c|c|c|c|}
\hline $\begin{array}{l}\text { Author, year } \\
\text { [ref] }\end{array}$ & Schedule & Phase & \# patients & Results & $\begin{array}{l}\text { Primary } \\
\text { aim }\end{array}$ \\
\hline $\begin{array}{l}\text { Chang, } 2010 \\
\text { [8] }\end{array}$ & $\begin{array}{l}\text { Cet- } \\
\text { containing } \\
\text { chemo }\end{array}$ & Retrospective & 5 & $\begin{array}{l}1 \mathrm{CR}+3 \mathrm{PR}+1 \mathrm{SD} \\
\text { PFS 4-16 months }\end{array}$ & \\
\hline $\begin{array}{l}\text { Borbath, } \\
2013 \text { [9] }\end{array}$ & Cet + Gem & II & 44 & $\begin{array}{l}6 \text { months PFS }=47 \% \\
\text { OS }=13.5 \text { months } \\
\text { ORR }=20.4 \%\end{array}$ & $\begin{array}{l}6 \text { months } \\
\text { PFS } \\
\text { Met }\end{array}$ \\
\hline $\begin{array}{l}\text { Malka, } 2014 \\
{[10]}\end{array}$ & $\begin{array}{l}\text { GEMOX } \pm \\
\text { Cet }\end{array}$ & $\begin{array}{l}\text { II } \\
\text { Randomised }\end{array}$ & 150 & GEMOX vs GEMOX + Cet & NA \\
\hline $\begin{array}{l}\text { Paule, } 2007 \\
{[11]}\end{array}$ & $\begin{array}{l}\text { GEMOX + } \\
\text { Cet }\end{array}$ & Retrospective & 9 & $\begin{array}{l}\text { In IH CCA only GEMOX pretreated } \\
2 \text { PR (ORR }=22 \%)\end{array}$ & NA \\
\hline $\begin{array}{l}\text { Gruenberger, } \\
2010 \text { [12] }\end{array}$ & $\begin{array}{l}\text { GEMOX + } \\
\text { Cet }\end{array}$ & & 30 & $\begin{array}{l}60 \% \text { of the patients had IH CCA } \\
\text { ORR }=63 \%\end{array}$ & $\begin{array}{l}\text { ORR } \\
\text { Met }\end{array}$ \\
\hline $\begin{array}{l}\text { Chen, } 2015 \\
\text { [13] }\end{array}$ & GEMOX \pm & $\begin{array}{l}\text { II } \\
\text { Randomised }\end{array}$ & 122 & $\begin{array}{l}\text { GEMOX + Cet vs GEMOX } \\
\text { ORR }=27 \% \text { vs } 15 \%(p=0.12) \\
\text { PFS }=6.7 \text { vs } 4.1 \text { months }(p=0.05) \\
\text { OS }=10.6 \text { vs } 9.8 \text { months }(p=0.91)\end{array}$ & $\begin{array}{l}\text { ORR } \\
\text { Not Met }\end{array}$ \\
\hline
\end{tabular}

Cet = Cetuximab; Gem = Gemcitabine; GEMOX = Gemcitabine and oxaliplatin; ORR = Overall Response Rate; $\mathrm{DCR}=$ Disease Control Rate; $\mathrm{CR}=$ Complete Response; $\mathrm{PR}=$ Partial Response; $\mathrm{SD}=$ Stable Disease; $\mathrm{OS}=$ Overall Survival; PFS = Progression Free Survival; NA = Not Assessable

$\mathrm{CCA}=$ Cholangiocarcinoma; $\mathrm{IH}=$ Intrahepatic 
Table 2. Key results of trials exploring panitumumab in locally advanced or metastatic CCA patients

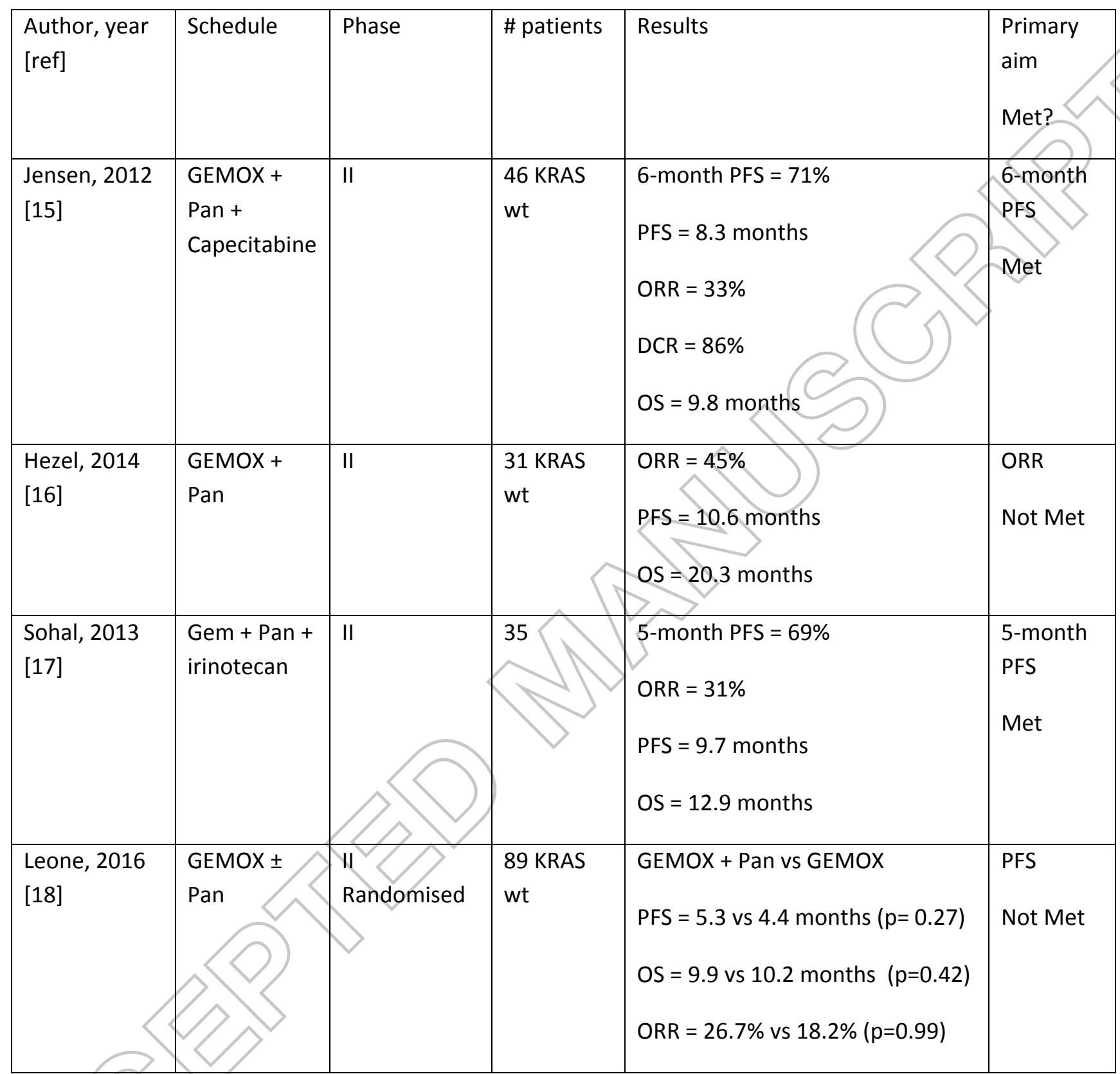

Pan = Panitumumab; Gem = Gemcitabine; GEMOX = Gemcitabine and oxaliplatin; $w$ t $=$ wild type; ORR = Overall Response Rate; $\mathrm{DCR}=$ Disease Control Rate; $\mathrm{CR}=$ Complete Response; $\mathrm{PR}=$ Partial Response; $\mathrm{SD}=$ Stable Disease; OS = Overall Survival; PFS = Progression Free Survival; NA = Not Assessable

CCA = Cholangiocarcinoma; $\mathrm{IH}=$ Intrahepatic 
Table 3. New agents under evaluation in CCA patients grouped according to inhibition target or novelty of action

\begin{tabular}{|c|c|c|c|}
\hline Drug & $\begin{array}{l}\text { Class } \\
\text { Target }\end{array}$ & \begin{tabular}{|l|} 
Stage of \\
development in \\
CCA \\
\end{tabular} & Note \\
\hline \multicolumn{4}{|c|}{ HER Family } \\
\hline Cetuximab & $\mathrm{Ab}$ & Random Phase II & Not superior to CT alone \\
\hline Panitumumab & $\mathrm{Ab}$ & \begin{tabular}{|l|} 
Random Phase II \\
\end{tabular} & Not superior to $\mathrm{CT}$ alone \\
\hline Erlotinib & TKI & Phase III & Not superior to CT alone \\
\hline Trastuzumab & $A b$ & Phase II & Ongoing. Slow accrual \\
\hline Lapatinib & TKI & Phase II & Abandoned \\
\hline ASLAN001 & TKI & Phase II & Ongoing \\
\hline \multicolumn{4}{|c|}{ mTOR } \\
\hline Everolimus & Small mol & Phase II & Results not clinically relevant \\
\hline \multicolumn{4}{|c|}{ VEGF } \\
\hline Bevacizumab & $\mathrm{Ab}$ & Phase II & Not approved \\
\hline Ramucirumab & $A b$ & Phase II & Ongoing. No result posted \\
\hline Cediranib & TKI & Random Phase II & Not superior to $\mathrm{CT}$ alone \\
\hline Regorafenib & TKI & Phase II & Ongoing \\
\hline Sorafenib & TKI & Two-step Phase II & $\begin{array}{l}\text { Terminated after first step. No } \\
\text { clinical activity }\end{array}$ \\
\hline Sunitinib & TKI & Phase II & Ongoing \\
\hline Pazopanib & TKI & Phase II & Ongoing \\
\hline \multicolumn{4}{|c|}{ FGFR } \\
\hline Infigratinib & TKI & Phase II & Ongoing \\
\hline ARQ087 & TKI & Phase II & $\begin{array}{l}\text { Ongoing in solid tumours } \\
\text { including CCA }\end{array}$ \\
\hline \multicolumn{4}{|c|}{ ALK } \\
\hline Ceritinib & & Phase II & $\begin{array}{l}\text { Ongoing in ROS1/ALK over- } \\
\text { expressed CCA }\end{array}$ \\
\hline Entrectinib & & Phase I/II & $\begin{array}{l}\text { Ongoing in solid tumours with } \\
\text { NTRK1-3, ROS or ALK molecular } \\
\text { alterations }\end{array}$ \\
\hline \multicolumn{4}{|c|}{ ABL } \\
\hline Bosutinib & TKI & Phase II & Abandoned \\
\hline Imatinib & TKI & Phase II & Low clinical activity. Abandoned \\
\hline \multicolumn{4}{|c|}{ MEK } \\
\hline Trametinib & TKI & Phase II & Waiting for results \\
\hline Selumetinib & TKI & Phase I & Phase II not yet proposed \\
\hline \multicolumn{4}{|c|}{ PI3K AKT } \\
\hline Buparlisib & Small mol & Phase II & $\begin{array}{l}\text { Lack of accrual in solid tumours. } \\
\text { Not in development }\end{array}$ \\
\hline MK2206 & Small mol & Phase II & Limited clinical activity \\
\hline \multicolumn{4}{|c|}{ FARNESYLTRANSFERASE } \\
\hline Lonafarnib & Small mol & Phase II & $\begin{array}{l}\text { Protocol withdrawn before } \\
\text { enrolment }\end{array}$ \\
\hline Tipifarnib & Small mol & Phase I & Not more in development \\
\hline
\end{tabular}




\begin{tabular}{|c|c|c|c|}
\hline Bortezomib & Small mol & Two-step Phase II & $\begin{array}{l}\text { Terminated after first step. } \\
\text { Limited clinical activity }\end{array}$ \\
\hline \multicolumn{4}{|c|}{ MULTITARGET } \\
\hline Vandetanib & TKI & Random Phase II & Not superior to CT alone \\
\hline Merestinib & TKI & Phase II & Ongoing \\
\hline Cabozantinib & TKI & Phase II & Ongoing \\
\hline Dasatinib & TKI & Phase II & Ongoing in IDH-mutant CCA \\
\hline \multicolumn{4}{|c|}{ NOVEL AGENTS } \\
\hline DKN-01 & Ab antiDkk-1 & Phase I/II & Ongoing with cisplatin + gem \\
\hline Saracatinib & TKI binding to Src Family & Phase I & $\begin{array}{l}\text { MTD determined in solid } \\
\text { tumours, including CCA }\end{array}$ \\
\hline Exerin & $\mathrm{N}$-cadherin inhibitor & Phase I & Ongoing with cisplatin + gem \\
\hline Silmitasertib & $\begin{array}{l}\text { CK2 (serine/threonine } \\
\text { kinase) inhibitor }\end{array}$ & Phase I/II & Ongoing with cisplatin + gem \\
\hline AG881 & $\begin{array}{l}\text { Pan-IDH mutant } \\
\text { inhibitor }\end{array}$ & Phase I & $\begin{array}{l}\text { Ongoing in solid tumours, } \\
\text { including CCA }\end{array}$ \\
\hline OXY111A & Oxygen modulator & Phase I/II & Ongoing \\
\hline PLX 8394 & BRAF inhibitor & Phase I/II & Ongoing \\
\hline Veliparib & PARP $1 / 2$ inhibitor & Phase I & $\begin{array}{l}\text { With cisplatin + gem. No results } \\
\text { have been published }\end{array}$ \\
\hline $\mathrm{RRx}-001$ & $\begin{array}{l}\text { Multiple epi-enzyme } \\
\text { inhibitor }\end{array}$ & Phase & Ongoing with cisplatin + gem \\
\hline Becatecarin & $\begin{array}{l}\text { Topoisomerase I } \\
\text { inhibitor }\end{array}$ & Pha & $\begin{array}{l}\text { Trial terminated in 2006. No } \\
\text { results available }\end{array}$ \\
\hline
\end{tabular}

